\title{
Onset of and recovery from physiological stress in Liocarcinus depurator after trawling and air exposure under different seasonal conditions
}

\author{
S. Raicevich $\cdot$ F. Giomi $\cdot$ F. Pranovi • \\ O. Giovanardi $\cdot$ P. Di Muro $\cdot$ M. Beltramini
}

Received: 27 May 2010/Revised: 16 December 2010/Accepted: 24 December 2010/Published online: 13 January 2011

(C) Springer Science+Business Media B.V. 2011

\begin{abstract}
The onset of and recovery from physiological stress in Liocarcinus depurator (Decapoda: Portunidae), that were trawled and subjected to emersion during fishing activities, was analysed in a field study in the Northern Adriatic Sea. Our working hypothesis intended to assess the development of physiological impairment due to air exposure during sorting operations, and the possible recovery trajectories after the return to sea of this by-caught species. The protocol we used included experimental trawling and quantification of physiological stress indicators (haemolymph concentrations of L-lactate, D-glucose, ammonia and $\mathrm{pH}$ ) under different seasonal conditions. Immediately after being caught, when the fishing net was emptied on board, L. depurator showed higher physiological imbalance in the summer vs. winter
\end{abstract}

Handing editor: Stuart Jenkins

S. Raicevich · O. Giovanardi

ISPRA, Istituto Superiore per la Protezione e la Ricerca Ambientale, Loc. Brondolo, 30015 Chioggia (Venezia), Italy

F. Giomi · P. Di Muro · M. Beltramini ( $\square)$

Department of Biology, University of Padova,

Viale G. Colombo 3, 35131 Padova, Italy

e-mail: mariano.beltramini@unipd.it

\section{F. Pranovi}

Enviromental Sciences, Informatics and Statistic Department, Università Ca' Foscari, Castello 2737/b, 30122 Venice, Italy experiments, highlighting the immediate effect of temperature shock due to the difference in temperature between the sea bottom and the deck (15-18 and $2^{\circ} \mathrm{C}$ in summer and winter, respectively). Experimental animals in the permanently emersed condition exhibited a progressive disruption of homeostasis in both seasons, as confirmed by a significant increase in lactate and a decrease in the $\mathrm{pH}$ of the haemolymph as a function of the emersion time. Ammonia levels were almost stable in the summer, when the physiological limits of this metabolite were reached immediately after animals were caught. In the winter, a significant increase in ammonia was observed over the time. This pattern can be attributed to the impairment of gill function, resulting in suffocation (manifested by marked haemolymph acidosis) and reduced ammonia excretion. Glucose concentration was revealed to be stable during air exposure in both seasons, though a higher concentration was recorded in the summer compared to the winter. The recovered individuals tended to return to pre-caught values for all of the haemolymph parameters we measured, though with different trajectories in the two seasons. From these results, we conclude that temperature shock, coupled with air exposure, influenced the ultimate stress level of this species to a greater extent than other effects of fishing.

Keywords Physiological stress - Emersion · Temperature shock · Recovery · Fishing disturbance . Decapods 


\section{Introduction}

A large proportion of the total catch in demersal fishing activities, such as otter-trawl and beam-trawl fisheries, may be represented by by-catch species that will be discarded (Kelleher, 2005). Therefore, it is not surprising that in the last decade a substantial effort has been made to understand and quantify processes involved in producing discard (see Kelleher, 2005) and to evaluate potential effects of these processes at different hierarchical levels, including individual and population levels (Broadhurst et al., 2006).

It is now well established that, during the fishing process, including capture by fishing gear and air exposure on deck during sorting operations, individuals in the catch may experience physical damage (Bergmann et al., 2001a; Pranovi et al., 2001) and temperature and/or pressure shocks that may lead to physiological impairment (Bergmann et al., 2001b), which may ultimately result in high mortality rates (Giomi et al., 2008). At the same time, individuals escaping through the net may suffer physical, physiological and behavioural consequences (Harris \& Andrews, 2005a, b) that could reduce their chances of survival, e.g., by increasing their vulnerability to predation. In heavily exploited fishing grounds, depletion of local populations and, in the worst-case scenario, the extirpation of the most vulnerable species, may result (Dulvy \& Reynolds, 2002).

Several factors have been identified to play an important role in determining the sensitivity of nontarget species to the fishing process, such as the fragility of their body, physiological and life-history traits, and technical features of the fishing gear (MacDonald et al., 1996). Other aspects of the fishing process, such as duration of the tow and of sorting as well as the local environmental conditions (e.g., the presence of a strong thermocline or halocline and air temperature), are also thought to play an important role in determining the ultimate fate of discarded specimens (Broadhurst et al., 2006; Lund et al., 2009). A study carried out by Bergmann et al. (2001b) highlighted that being subjected to capture and subsequent exposure on deck can induce severe physiological impairment in decapods, such as Liocarcinus depurator and Munida rugosa, and the recovery of these species to unperturbed physiological conditions requires approximately $24 \mathrm{~h}$ after re-immersion. The role of environmental features as fundamental drivers influencing the immediate stress level and mortality in discard species was further investigated in $L$. depurator by Giomi et al. (2008), highlighting higher values of stress indicators in the summer than in the winter.

This work, which sought to further develop the results reported by Giomi et al. (2008), aimed to assess how seasonal temperature affects the time dependency of the onset of physiological impairment during the process of sorting and recovery after reimmersion. Upon emersion, a collapse of the lamellate and the filamentous gills occurs (McMahon, 2001), hence decreasing the rate of exchanges at their level. The impairment of oxygen uptake shifts the tissue metabolism to anaerobic, increasing lactate concentrations. This effect, together with the rise of carbon dioxide, causes respiratory acidosis. The gill collapse also impairs the ammonia excretion across gills increasing concentration of this metabolite in the haemolymph and tissues (Danford et al., 2002). Moreover, the organisms respond to trawling and the emersion with mechanical exercise reflected in hyperglycemia caused by the increased glycogen utilisation (Hagerman et al., 1990).

Liocarcinus depurator is a good case study for the following reasons: (i) it represents an important fraction of the discarded species in many marine fisheries (Pranovi et al., 2001; Bergmann et al., 2002a); (ii) it could play an important ecological role within the benthic communities because it is both a predator and a potential scavenger (Hall et al., 1990); (iii) it has a sublittoral distribution below the seasonal thermocline, making it more vulnerable to thermal shocks; (iv) it shows a wide geographical distribution, from the Mediterranean Sea to the North Sea (Rufino et al., 2005).

Our working hypothesis was tested by replicating the on-board experimental protocol in two different seasons (late winter 2002 and summer 2003). Indicators of physiological stress (haemolymph L-lactate, D-glucose, ammonia, and $\mathrm{pH}$ ) were recorded over time in individuals exposed to air after trawling and after re-immersion in water. Our results are also discussed in the context of the ecological significance of fishing disturbance at the population level. 


\section{Materials and methods}

Study area and environmental features

Samples were collected in an area $\left(\sim 8 \times 8 \mathrm{~km}^{2}\right)$ located in the Northern Adriatic Sea approximately $35 \mathrm{~km}$ off the Italian coast on a soft bottom at a depth of $\sim 30 \mathrm{~m}$ during surveys that were carried out in the late winter (beginning of March 2002) and summer (July 2003). The sea surface temperature was $11.0^{\circ} \mathrm{C}$ in the winter and $26^{\circ} \mathrm{C}$ in the summer, whereas the air temperatures that were recorded were $9.0-12.0$ and $26-28^{\circ} \mathrm{C}$ for the winter and the summer, respectively. These data are in agreement with data from national oceanographic surveys that were carried out by the Institute Ruder Boskovic (Rovinj, Croatia) in the same area and over the same sampling period, which recorded sea surface temperatures of 11.5 and $26.0^{\circ} \mathrm{C}$ and sea bottom temperatures of 9.0 and $11.5^{\circ} \mathrm{C}$ in the winter and the summer, respectively (Robert Precali, personal communication). These surveys found that the sea bottom and sea surface salinity ranged from 38.0 to $35.0 \mathrm{PSU}$ in the winter and 38.2 to $36.9 \mathrm{PSU}$ in the summer. According to these data, L. depurator caught in winter were subjected to negligible thermal shock from the sea bottom to the deck $\left(2-3^{\circ} \mathrm{C}\right)$ compared to those caught in summer $\left(15-18^{\circ} \mathrm{C}\right)$. In both seasons, no salinity shocks occurred.

Fishing operations and Liocarcinus depurator sampling

Liocarcinus depurator samples were collected during two experimental tows per season (40 min at a speed of $11 \mathrm{~km} \mathrm{~h}^{-1}=5.9 \mathrm{kt}$ ) that were carried out using a commercial fishing vessel equipped with rapido trawl fishing gear (a type of beam trawl; for details see Pranovi et al., 2001).

Immediately after deck operations, which consisted in retrieving and emptying the net on board, lasting approximately 5-7 min, intermoult (according to the classification proposed by Mangum, 1985) live, adult specimens were randomly collected from the catch and immediately employed for use in the physiological stress experiments.

Physiological stress onset experiment

To investigate physiological changes related to the duration of air exposure, haemolymph was drawn once from each individual left exposed to the air for the purpose of measuring metabolite concentrations. Haemolymph withdrawal took $0.5-1$ min per specimen. Overall sampling lasted $45 \mathrm{~min}$ in winter ( $n=33$ individuals) and $35 \mathrm{~min}$ (no individual survived longer) in summer ( $n=66$ individuals). These intervals were consistent with the duration of the sorting process during commercial fishing activities (Pranovi et al., 2001). Reference levels for metabolite concentrations were assessed in individuals collected by means of baited creels to reduce the potential stress induced by active fishing (control group, "C"; $n=6$ ). Due to the accidental loss of creels in summer, control individuals $(n=6)$ were collected by means of a very short $(5 \mathrm{~min})$ and slow tow $\left(5 \mathrm{~km} \mathrm{~h}^{-1}=2.7 \mathrm{kt}\right)$. After being caught, control individuals were immediately transferred into tanks with running seawater, and haemolymph was collected within 8 min after the re-immersion.

Physiological stress recovery experiment

The pattern of recovery after air exposure was investigated. Air exposure lasted for $60 \mathrm{~min}$ in the winter but just $5 \mathrm{~min}$ in the summer, due to the high mortality rate recorded in summer (see Giomi et al., 2008). At the end of the air exposure period (EAE), individuals were introduced into shaded single cages immersed in a tank supplied with running seawater kept at sea bottom temperature. For the winter experiment, the haemolymph was withdrawn from individuals ( $n=6$ in all treatments) at EAE and during the recovery period at $0.5,1,2,4,8,12$, and $24 \mathrm{~h}$ after the EAE. In summer, due to the scarcity of live individuals, haemolymph was sampled at $0.5,1$, 2,3 , and $5 \mathrm{~h}$ after the $\operatorname{EAE}(n=6$ in all treatments other than the last two groups, where $n=5$ and 3 , respectively).

Haemolymph withdrawal and metabolite concentration determination

Haemolymph was collected from individuals using a 1-ml syringe that was inserted into the pericardium from the posterior side of the carapace to reduce the duration of handling and to collect post-branchial blood. It is worth noting that the sampling itself induces some stress; accordingly, the withdrawal procedure was set in order to reduce as much as 
possible the handling duration. The additional stress induced by handling was therefore minimised, although it is impossible to remove this noise completely. Samples were immediately frozen and kept in liquid nitrogen until arrival in the lab, where they were stored at $-20^{\circ} \mathrm{C}$ until use. L-lactate, D-glucose, and ammonia concentrations in haemolymph samples were assessed as described by Giomi et al. (2008). In addition, the $\mathrm{pH}$ was measured in the total haemolymph with a Radiometer mod. PHM82 microelectrode (Radiometer, Denmark) according to the procedure described by Bergmann et al. (2001b).

\section{Statistical analyses}

In the physiological stress onset experiments, the linear regression between the duration of exposure to air (minutes) and metabolite concentrations and $\mathrm{pH}$ was calculated for each season and then compared. The early phase of the recovery process following physiological impairment (i.e., samples that were collected at the EAE and at $0.5,1$, and $2 \mathrm{~h}$ after reimmersion in running sea water) was also compared. To test the effects of the season and the experimental time and their interaction, a two-way factorial analysis of variance (ANOVA) was applied for each parameter; data were $\log (x+1)$ transformed prior to the analyses in order to achieve the homogeneity of variance. Post-hoc pairwise comparisons between treatments within each season were carried out by means of Tukey's HSD test (Tukey, 1953). Finally, samples collected at the end of the recovery period (24 and $5 \mathrm{~h}$ after EAE in the winter and summer, respectively) were compared with the corresponding seasonal control and EAE groups using the MannWhitney $U$ test, since the assumptions of normality were violated.

\section{Results}

Physiological stress onset

At the beginning of the exposure-to-air phase of experiments, immediately after being caught, higher haemolymph metabolite concentrations and lower $\mathrm{pH}$ values were recorded in both seasons compared to the respective control groups (Fig. 1). Particularly severe increases were recorded in the summer for glucose and in the winter for lactate, while in the other cases, differences compared to control values were less pronounced. It is worth noting that in the summer, there was higher variability in control samples. In the summer, significantly higher concentrations of glucose, lactate, and ammonia, and lower $\mathrm{pH}$ values were recorded compared to the winter (Mann-Whitney $U$ test, $P<0.01$ in all comparisons). During emersion, the levels of metabolites and $\mathrm{pH}$ were found to be influenced by the duration of the exposure to air to a different extent in the two seasons (Fig. 1).

No significant regression with experimental time were detected for glucose; values ranged between 0 to 2 and 5 to $7 \mathrm{mmol}^{-1}$ in the winter and summer experiments, respectively (Fig. 1a). Lactate concentration increased significantly $(P<0.001)$ as a function of time in the summer, whereas the increase observed in the winter was not significant (Fig. 1b). In contrast, ammonia significantly increased with the time of the air exposure in winter $(P<0.05)$, whereas in the summer no significant trend was recorded (Fig. 1c). Finally, $\mathrm{pH}$ was characterised by similar patterns of decreasing with time in both the winter and summer (Fig. 2d), but in the summer, data were more variable. Because of this, the trend in $\mathrm{pH}$ was only significant in the winter $(P<0.01)$.

\section{Recovery from physiological impairment}

Higher variability of data was observed in summer compared to the winter and in the early stages of the recovery process. However, in general terms, after air exposure the metabolite concentrations showed a decrease over time and $\mathrm{pH}$ increased, exhibiting a pattern that was compatible with recovery from acidosis (Fig. 2). The results of statistical analysis are summarised in Table 1.

For glucose levels (Fig. 2a), a significant interaction between the season and the experimental time was seen in the early phase of recovery (EAE-2 h; two-way ANOVA; season $\times$ time: $F_{3,47}=24.5 ; P<0.001$ ). In the winter, glucose showed an increasing trend with a peak at $2 \mathrm{~h}\left(2.5 \mathrm{mmol}^{-1}\right)$, when a significantly higher value was recorded compared to EAE (Tukey's HSD, $P<0.001)$. Afterwards, the glucose level decreased, reaching a significantly lower value than at EAE at the end of the experiment $(24 \mathrm{~h})$ (MannWhitney $U$ test, $P<0.01)$. At this stage, the observed 

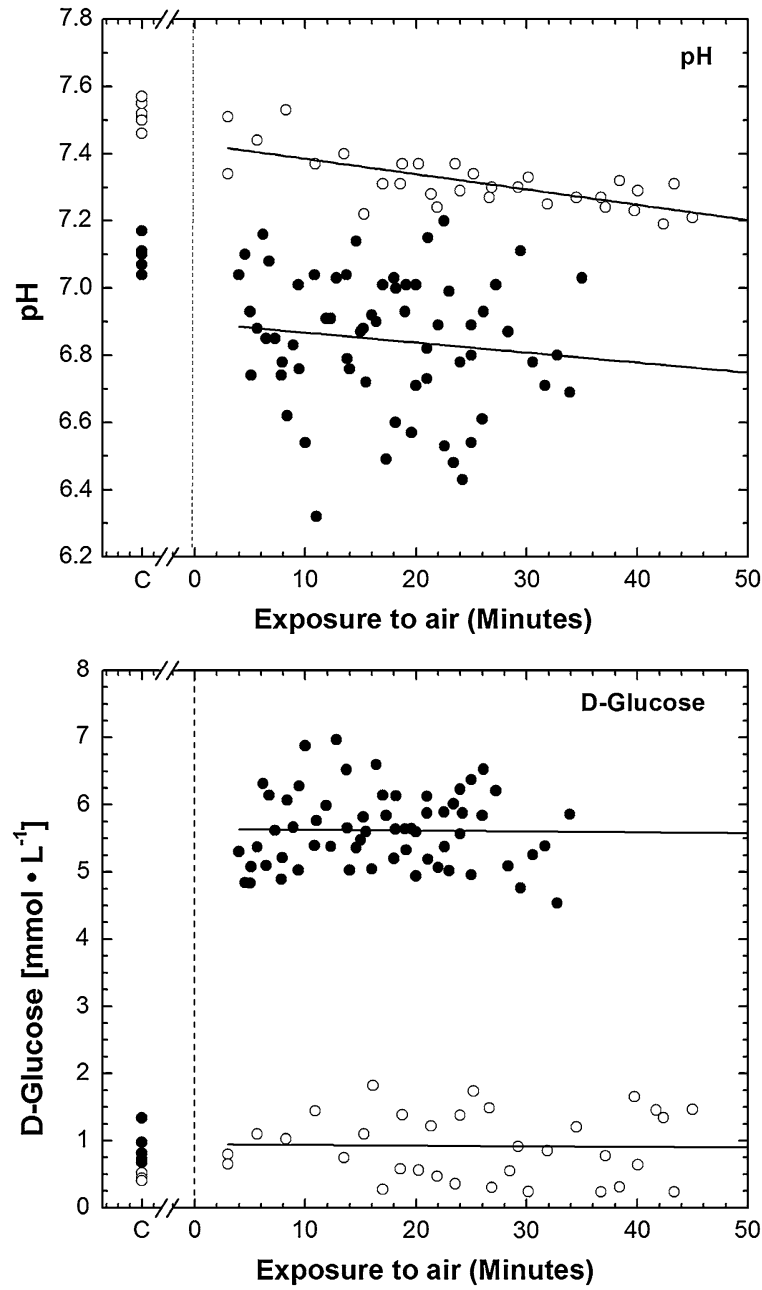

Fig. 1 Trends of D-glucose, L-lactate and ammonia concentration $\left(\mathrm{mmol} \mathrm{l}^{-1}\right)$ and $\mathrm{pH}$ as a function of time in haemolymph samples of Liocarcinus depurator exposed to air after

levels of glucose (about $0.5 \mathrm{mmol}^{-1}$ ) were similar to those recorded in control individuals. In contrast, in summer, the glucose concentration decreased from $0.5 \mathrm{~h}$ (when it was approximately $4.5 \mathrm{mmol}^{-1}$ ) onwards. At the end of the recovery process, a significantly lower concentration of glucose compared to the concentration at EAE was recorded (MannWhitney $U$ test, $P<0.01$ ). This value was, however, significantly higher than that observed in the control group (Mann-Whitney $U$ test, $P<0.05$ ).

Overall, the time dependence of the lactate concentration was similar in the two seasons (Fig. 2b), though concentrations were higher in the winter
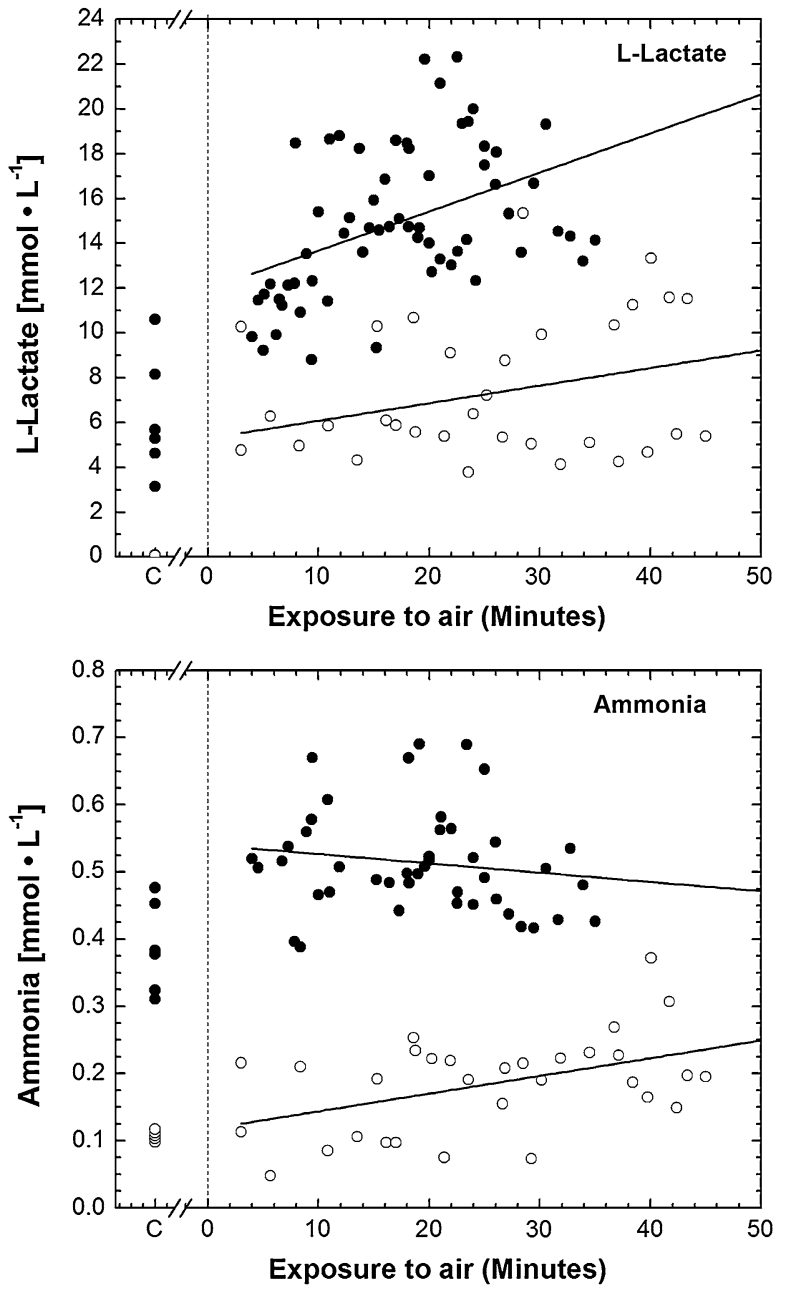

trawling in the winter (open circle) and the summer (filled circle). The estimated linear trend is superimposed. $C$ control groups

compared to the summer (two-way ANOVA; season: $F_{1,47}=76.2 ; P<0.001$ ), and fluctuations over time were recorded in the early phase of the recovery period (two-way ANOVA; time; $F_{3,47}=6.5 ; P<$ $0.01)$. In winter, at the end of the experiment, the recovery could be considered to be almost complete because lactate stabilised to significantly lower values compared to EAE (Mann-Whitney $U$ test, $P<0.01$ ), reaching similar levels to those observed in controls $\left(0.1-0.2 \mathrm{mmol}^{-1}\right)$. In the summer, the decreasing trend in lactate levels was more evident from $3 \mathrm{~h}$ after EAE onwards. In addition, the lactate concentrations at the end of the recovery period were 

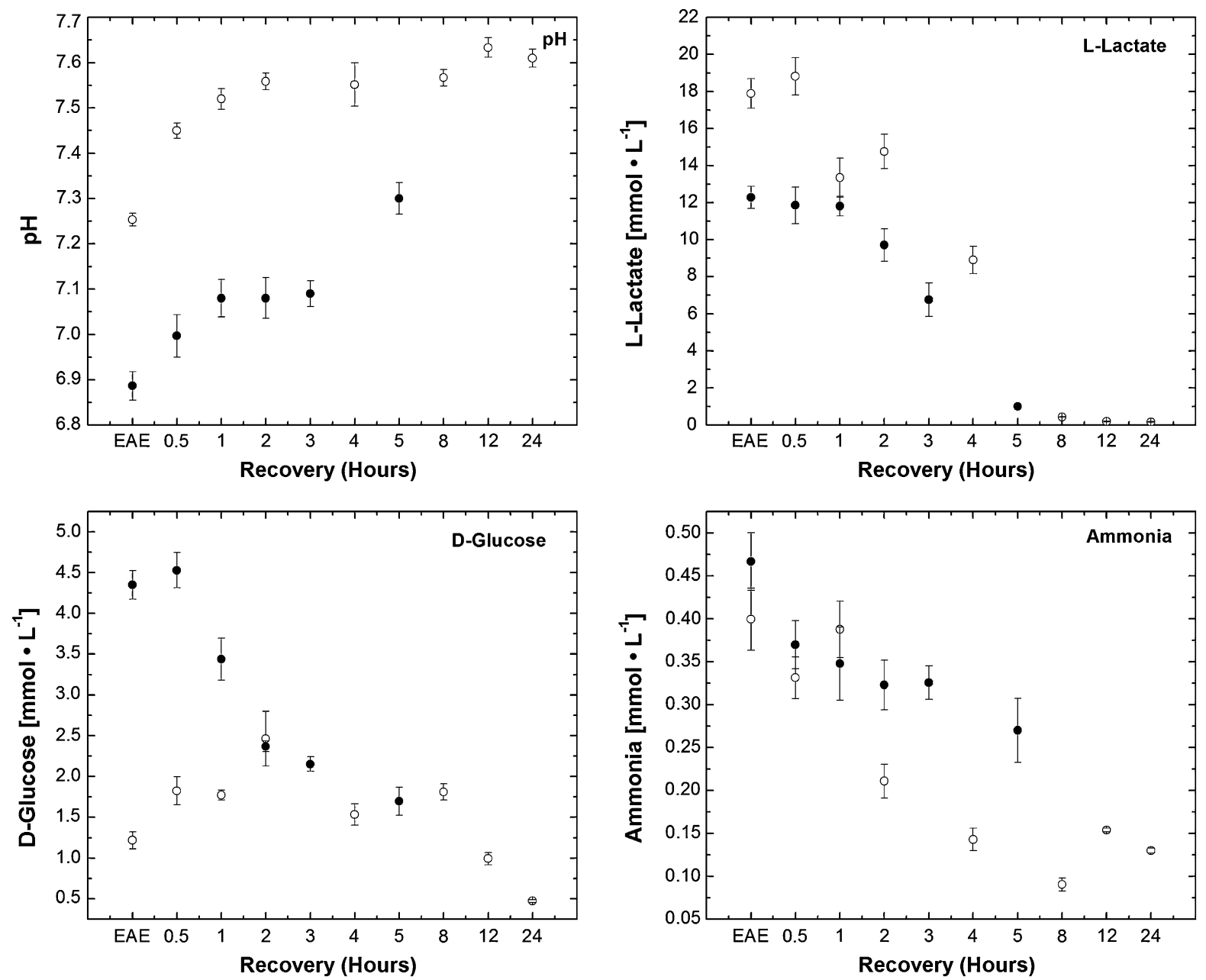

Fig. 2 Time dependence of mean $( \pm \mathrm{SE})$ D-glucose, L-lactate and ammonia concentration $\left(\mathrm{mmol} \mathrm{l}^{-1}\right)$ and $\mathrm{pH}$ in haemolymph samples from Liocarcinus depurator exposed to air after trawling and reimmersion in water in the winter (open circle)

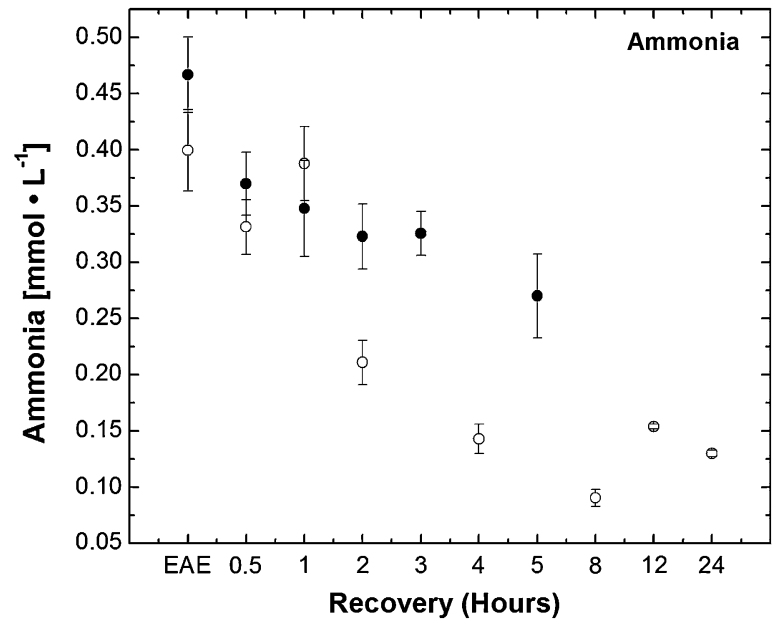

and the summer (filled circle) experiments. EAE end of the air exposure period; $0.5,1,2,3,4,5,8,12,24 \mathrm{~h}$ after the reimmersion of crabs in tanks filled with running sea water

significantly lower than the levels at EAE and in the control group (Mann-Whitney $U$ test, $P<0.05$ in both comparisons).

In the case of ammonia (Fig. 2c), different trends were observed between the two seasons in the early phase of the recovery (two-way ANOVA; season $\times$ time: $\left.F_{3,47}=3.3 ; P<0.05\right)$. The winter values remained almost constant up to $1 \mathrm{~h}$ after EAE (about $0.4 \mathrm{mmol}^{-1}$ ), while significantly lower values compared to EAE were observed after $2 \mathrm{~h}$ (Tukey's HSD, $P<0.001)$. At the end of the winter recovery experiment, the ammonia concentration reached a value of approximately $0.12 \mathrm{mmol} \mathrm{l}^{-1}$, which was significantly lower than at EAE (Mann-Whitney

$U$ test, $P<0.05)$ and similar to the value recorded in controls (approximately $0.114 \mathrm{mmol} \mathrm{l}^{-1}$ ). However, the pairwise comparison revealed a significant difference in ammonia levels over the course of the recovery period (Mann-Whitney $U$ test, $P<0.05$ ). In contrast, during the summer, the largest decrease in ammonia concentration was observed after the maximum level was recorded at EAE $\left(0.47 \mathrm{mmol} \mathrm{l}^{-1}\right)$, but up to $2 \mathrm{~h}$ after re-immersion, no significant differences between seasons were recorded. At the end of the recovery period, ammonia concentration was significantly lower compared to at EAE (Mann-Whitney $U$ test, $P<0.05)$ with values similar to those of the control group $\left(0.25 \mathrm{mmol} \mathrm{l}^{-1}\right)$. 
Table 1 Left panel: results of the two-way ANOVA test for the comparison of haemolymph parameters (D-glucose, L-lactate, ammonia, and $\mathrm{pH}$ ) at various stages of the recovery process of Liocarcinus depurator: at the end of air exposure (EAE) and at $0.5,1$, and $2 \mathrm{~h}$ after the reimmersion in running sea water (see Fig. 2). Right panel: results of Mann-Whitney $U$ test comparison between haemolymph parameters at the end of the recovery experiments $(24$ and $5 \mathrm{~h}$ in Winter and Summer, respectively) and the corresponding seasonal data at the end of air exposure (EAE) and in controls (C)

\begin{tabular}{|c|c|c|c|c|c|c|c|c|}
\hline Factor & df & SS & MS & $F$ & $P$ & Mann-Whitney $U$ test & & $P$ \\
\hline \multicolumn{9}{|l|}{ D-glucose } \\
\hline Season & 1 & 0.06 & 0.06 & 172.8 & $<0.001$ & Winter & $24 \mathrm{~h}$ vs. EAE & $<0.01$ \\
\hline Time & 3 & 0.00 & 0.00 & 1.4 & 0.26 & & $24 \mathrm{~h}$ vs. $\mathrm{C}$ & n.s. \\
\hline Season $*$ time & 3 & 0.3 & 0.01 & 24.5 & $<0.001$ & Summer & $5 \mathrm{~h}$ vs. EAE & $<0.01$ \\
\hline Error & 40 & 0.01 & 0.00 & & & & $5 \mathrm{~h}$ vs. $\mathrm{C}$ & $<0.05$ \\
\hline \multicolumn{9}{|l|}{ L-lactate } \\
\hline Season & 1 & 0.27 & 0.27 & 76.2 & $<0.001$ & Winter & $24 \mathrm{~h}$ vs. EAE & $<0.001$ \\
\hline Time & 3 & 0.07 & 0.02 & 6.5 & $<0.01$ & & $24 \mathrm{~h}$ vs. $\mathrm{C}$ & n.s. \\
\hline Season $*$ time & 3 & 0.02 & 0.01 & 2.1 & 0.12 & Summer & $5 \mathrm{~h}$ vs. EAE & $<0.05$ \\
\hline Error & 40 & 0.14 & 0.00 & & & & $5 \mathrm{~h}$ vs. $\mathrm{C}$ & $<0.05$ \\
\hline \multicolumn{9}{|l|}{ Ammonia } \\
\hline Season & 1 & 0.00 & 0.00 & 5.8 & $<0.05$ & Winter & $24 \mathrm{~h}$ vs. EAE & $<0.05$ \\
\hline Time & 3 & 0.02 & 0.01 & 11.0 & $<0.001$ & & 24 h vs. $\mathrm{C}$ & n.s. \\
\hline Season $*$ time & 3 & 0.01 & 0.00 & 3.3 & $<0.05$ & Summer & $5 \mathrm{~h}$ vs. EAE & $<0.05$ \\
\hline Error & 40 & 0.02 & 0.00 & & & & $5 \mathrm{~h}$ vs. $\mathrm{C}$ & n.s. \\
\hline \multicolumn{9}{|l|}{$\mathrm{pH}$} \\
\hline Season & 1 & 0.01 & 0.01 & 372.3 & $<0.001$ & Winter & $24 \mathrm{~h}$ vs. EAE & $<0.01$ \\
\hline Time & 3 & 0.00 & 0.00 & 25.2 & $<0.001$ & & $24 \mathrm{~h}$ vs. $\mathrm{C}$ & $<0.01$ \\
\hline Season $*$ time & 3 & 0.00 & 0.00 & 1.2 & 0.33 & Summer & $5 \mathrm{~h}$ vs. EAE & $<0.01$ \\
\hline Error & 40 & 0.00 & 0.00 & & & & $5 \mathrm{~h}$ vs. $\mathrm{C}$ & $<0.05$ \\
\hline
\end{tabular}

Season and time: fixed factors, season * time: tested interaction. Significant $P$ values are shown in bold n.s. not significant

The $\mathrm{pH}$ increased immediately after EAE and onwards in both seasons (Fig. 2d). In the first part of recovery, $\mathrm{pH}$ values were higher in winter compared to summer (two-way ANOVA; season: $F_{1,47}=$ 372.3; $P<0.001)$, though a similar increasing trend over time was observed in both seasons (two-way ANOVA; Time: $F_{3,47}=25.2 ; P<0.001$; season $\times$ time: not significant). Significantly higher values compared to EAE were recorded from 0.5 and $1 \mathrm{~h}$ onwards after reimmersion in water in the winter and the summer, respectively (Tukey's HSD, $P<$ 0.01 in all comparisons). In both seasons, at the end of the recovery period, the $\mathrm{pH}$ value was significantly higher than that observed in the respective control groups or in the EAE samples (Mann-Whitney $U$ test, $P<0.01$ in all comparisons, with the exception of the comparison between the control group and the end of the recovery process in the summer experiment, where $P<0.05$ ).

\section{Discussion}

The collateral mortality of species discarded during fishing activities is known to be affected by biological, environmental, and technical factors, and this represents one of the main causes of disturbance in non-target species (Broadhurst et al., 2006). This study was mainly focused on the effects of seasonal temperature variations on individuals being subjected to air emersion and then discarded.

As a major environmental factor, we focused on air temperature because it is known to strongly affect stress levels and mortality in discarded species 
(Broadhurst et al., 2006; Giomi et al., 2008). This potential source of stress is considered to play a fundamental role in all temperate fisheries, where thermal shock is likely to be more marked than other environmental features such as the presence of low salinity layers that may be relevant only at local/ regional scale. Because it could be difficult to reproduce all the complex interactions among possible sources of disturbance related to trawling under controlled conditions, laboratory-based experiments might underestimate ultimate effects of fishing on the fate of discarded species (Harris \& Ulmestrand, 2004). For this reason, we decided to adopt a fieldbased approach in two different seasons. The duration of the tow and of air exposure used in the experiments was designed to mimic commercial fishing practices to evaluate the physiological stress induced by trawling activity in $L$. depurator.

During the summer experiment, $L$. depurator underwent a sharp temperature shock, first when the net was retrieved on board, passing the caught species above the thermocline, and then during the following sorting operations (representing approximately $15-18^{\circ} \mathrm{C}$ of temperature difference between air and the sea bottom). In contrast, during the winter, no large temperature differences were recorded between the sea bottom and the air temperature (less than $2^{\circ} \mathrm{C}$ ). In both seasons, only small variations in salinity were recorded in the water column (about 1.5-3 PSU), thus allowing us to exclude the possibility that $L$. depurator individuals were substantially influenced by this parameter during the retrieval of the net.

Values of physiological stress indicators that we recorded in the winter experiments were comparable with results that have been reported for the Clyde Sea (Bergmann et al., 2001b), with the exception of glucose levels, which showed markedly higher values in our study, indicating that the mechanical/physical stress associated with rapido trawling can induce a higher degree of physiological impairment compared to otter trawling. In contrast, our summer catches revealed that all physiological parameters undergo to a more pronounced imbalance in this season, exhibiting a sudden shift to sub-lethal conditions and a higher accumulation of toxic end products.

Comparison of controls and samples collected at the beginning of the emersion phase allowed us to estimate the role of trawling in the onset of physiological stress in L. depurator under different air temperature conditions. It must be considered, however, that crabs collected immediately after trawling (i.e., when the nets were emptied on deck) were also subjected to a pressure shock and to a short, but not negligible, exposure to air (5-7 $\mathrm{min})$, also in addition to a temperature shock during the summer. Thus, in addition to the mechanical and physical stress due to trawling, crabs also experienced emersion and temperature stress, though for a limited time interval. Indeed, a significant shift to anaerobic metabolism at the beginning of the emersion experiment is indicated by the increase in lactate concentrations in the haemolymph. At the same time, the impairment of the excretory process is revealed by ammonia accumulation (Durand et al., 1999; Danford et al., 2002). The decrease in $\mathrm{pH}$ that we observed in these experiments can be explained by the fact that, during emersion, sublittoral crustaceans typically show an increase of carbon dioxide in the haemolymph, which constitutes a primary source of acid. The disruptive effect of trawling and short-term emersion is also evident from observations of hyperglycaemia, which is attributable to an increased mobilisation of glycogen that is typically induced by crustacean hyperglycaemic hormone under stress conditions (Santos \& Keller, 1993).

Our results point to a clear role of air temperature in the disruption of homeostasis during the summer when the lower oxygen supply was combined with the temperature-dependent increase in metabolic rate. Loss of gill functionality combined with an increased rate of metabolic turnover also explains the more marked acidosis of the haemolymph in the summer vs. the winter experiment. Hypercapnia, together with lactate accumulation, progressively produces marked respiratory acidosis and suffocation, possibly resulting in death if animals do not recover in the water (Henry \& Wheatly, 1992). This is principally due to the collapse of the gills, which normally excrete these metabolites and prevent toxic accumulation (Cameron, 1979; McMahon \& Wilkens, 1983). The higher stability of glucose during emersion in the summer compared to the winter can also be explained by the temperature dependency of this parameter.

Taken together, our findings suggest that the time spent between retrieving and emptying the rapido trawling gear on board and during the beginning of haemolymph withdrawal was sufficient, in the summer experiment, to induce substantial physiological 
disruption in L. depurator. This conclusion is also consistent with seasonal differences in survival rates that have been reported for $L$. depurator by Giomi et al. (2008). These authors observed high survival rates during emersion in the winter (consistent with the results of Bergmann \& Moore (2001) survival tests) compared to the summer, when a dramatic immediate decrease in survival was recorded. In particular, the high concentration of ammonia observed in the present study in the summer, and its stability over time, could partially explain the high mortality rates that have been observed in $L$. depurator, as has been suggested for other subtidal crabs exposed to air (Durand et al., 1999, 2000).

Concerning the control groups, both sampling protocols were intended to have minimal impacts on specimens. However, it is conceivable that seasondependent disturbance (e.g., the displacement of animals from the sea bottom to the deck) differently affected haemolymph parameters in control animals; this might explain the differences observed between the control groups in the summer vs. the winter experiment. However, the general pattern of metabolite levels that we measured clearly suggests that temperature shock exerts a much stronger stress effect on $L$. depurator than do other effects induced by the fishing gear.

Comparing the winter and summer experiments, similar trends for lactate and $\mathrm{pH}$ were observed during the animals' recovery after EAE, though a higher level of physiological imbalance was recorded in the summer compared to the winter, confirming higher levels of acidosis in the warmer season. Lactate was rapidly removed and $\mathrm{pH}$ increased quickly in both seasons, suggesting a complete restoration of aerobic metabolism and recovery from acidosis after reimmersion in water. A notable difference in the pattern of lactate and $\mathrm{pH}$ levels in the early recovery process is represented by the opposite trends in glucose levels; the recovery phase in the winter experiment showed an increase in glucose concentration during the first phase of reimmersion, with a peak $2 \mathrm{~h}$ after EAE. This is in agreement with results of experiments on Cancer pagurus (Webster, 1996) and is a consequence of the progressive accumulation of crustacean hyperglycaemic hormone $(\mathrm{CHH})$, which regulates hyperglycaemia in the context of sudden hyperlactaemia. Hypoxia, emersion and temperature changes have all been recognised as stressful stimuli that increase the expression and release of $\mathrm{CHH}$ in the portunid crab Callinectes sapidus (Chung \& Zmora, 2008). Moreover, a similar delay in the reduction of glucose during the recovery period in the winter compared to the summer was observed by Lund et al. (2009) in trawled Nephrops norvegicus. The severe accumulation of glucose in the summer reveals that a stressful condition is already present in the trawled samples, suggesting a more drastic imbalance of carbohydrate metabolism and hormonal control in this season that results in a decrease in glucose concentration over the whole period of recovery. The reacquisition of excretory functions provides an explanation for the progressive decrease in ammonia, though it must be noted that, in the summer, a sudden reduction of this parameter was recorded immediately after the reimmersion in water compared to the winter when this process was slower, probably due to the lower metabolic rate associated with the lower water temperature. When individuals are discarded at sea, the physiological disruption and fatigue that are induced by the fishing process might cause detrimental behavioural effects. Morbidity and torpidity, together with impairment in tail flipping activities, were, in fact, recorded in decapods that had been discarded at sea (Haupt et al., 2006; Ridgway et al., 2006).

The physiological data that we collected in this work all show that $L$. depurator is vulnerable to the fishing process, particularly as a consequence of air exposure during the summer. This vulnerability might be explained by taking into consideration the ecological characteristics of this decapod, which is a sublittoral species and, hence, never subjected to air emersion and only rarely exposed to strong fluctuations in environmental parameters. Moreover, the distribution of $L$. depurator, which extends from Morocco to Norway, is centred in the temperate eastern Atlantic seaboard, and the Mediterranean probably provides a highest temperature range closer to the upper temperature tolerance of the species (Rufino et al., 2005). Exposure to air at high temperature does not appear to be sustainable for this species, though some mechanism of adaptation to hypoxic stress may exist, at least at the population level. For instance, heterogeneity in the composition of the subunits of haemocyanin, the oxygen transport protein, has been described in different populations of 
Liocarcinus spp., resulting in different oxygen binding properties (Giomi et al., 2007). All of this could play an important role at the population level in determining the abundance of this species within its main fishing grounds. High fishing pressure, coupled with the physiological impairment and high mortality rates that have been experimentally recorded, has been hypothesised to lead to population declines in the most vulnerable species (Broadhurst et al., 2006). Comparison with the data from trawl surveys that were carried out in the Adriatic Sea in 1982 (Šimunović, 1997) and 2006 (Fabi G., ISMAR CNR in Ancona, Italy, personal communication) shows, however, a rather stable spatial distribution of L. depurator over the last 24 years. A certain degree of stability in $L$. depurator populations could be ascribed to the fact that this species may reproduce several times per year in the Mediterranean Sea (Rufino et al., 2005), and, like other decapods, their larvae are dispersed according to local currents. Furthermore, fishing activity is often patchily distributed, and it is likely that some areas are never, or very rarely, fished. A recent study carried out in the Catalan Sea showed that $L$. depurator may sustain relatively high densities in heavily fished areas compared to undisturbed sites (deJuan et al., 2007), and it aggregates in tracks already disturbed by demersal fishing (Demestre et al., 2000). As a scavenger (Bergmann et al., 2002b), L. depurator makes use of supplementary, low-energy-expenditure sources of nutrition from injured or dead individuals that are discarded during fishing activities. Hence, it is possible to put forward the hypothesis of a sort of trade-off between the energetic costs associated with fishing disturbance and the energetic benefits of the discard supply. A similar process has been hypothesised in the North Sea by Ramsay et al. (2000) for the scavenging starfish Asterias rubens because these investigators observed a quadratic relationship between population density and fishing efforts.

\section{Conclusions}

In conclusion, the seasonal temperature shock determined by general oceanographic and climate conditions of fishing grounds exacerbates physiological stress in trawled individuals of $L$. depurator, and this effect is much stronger than the effects induced by fishing gear on physiological stress. Emersion during sorting operations progressively increases the disruption in homeostasis in this subtidal decapod, which is adapted to stable environments. When discarded at sea, stressed individuals recovered from the physiological imbalance induced by fishing activities, though this process was not immediate. Reduction in the duration of sorting time would be expected to be particularly effective for ensuring lower physiological disruption and higher survival rates for discarded L. depurator individuals. The forthcoming introduction of squared mesh in the cod-end (Council Regulation No. 1967/2006) and the use of benthos release panels could be very useful for this purpose because the reduction in total catches would result in a reduction in the number of total specimens caught and in a reduction in sorting duration.

Acknowledgements F. Da Ponte, G. Franceschini, A. Granzotto, M. Zucchetta and the captain and the crew of the F/V Ca Moro kindly helped during sampling operations. S. Mattiello technically supported the determination of metabolite concentrations. Dr. R. Precali, Institute Ruder Boskovic (Rovinj, Croatia), provided oceanographic data. Dr. G. Fabi, Istituto di Scienze del Mare (Ancona, Italy), provided data on $L$. depurator's spatial distribution in the central and northern Adriatic Sea. Research activities were supported by the Italian Ministry of Agricultural Policies (DG Fisheries and Aquaculture, Pr. 5A34) and University of Padova grants (60A06-1337/05).

\section{References}

Bergmann, M. \& P. G. Moore, 2001. Survival of decapod crustaceans discarded in the Nephrops fishery of the Clyde Sea area, Scotland. ICES Journal of Marine Science 58: 163-171.

Bergmann, M., D. J. Beare \& P. G. Moore, 2001a. Damage sustained by epibenthic invertebrates discarded in the Nephrops fishery of the Clyde Sea, Scotland. Journal of Sea Research 45: 105-118.

Bergmann, M., A. C. Taylor \& P. G. Moore, 2001b. Physiological stress in decapod crustaceans (Munida rugosa and Liocarcinus depurator) discarded in the Clyde Nephrops fishery. Journal of Experimental Marine Biology and Ecology 259: 215-229.

Bergmann, M., S. K. Wieczorek, P. G. Moore \& A. R. J. Atkinson, 2002a. Discard composition of the Nephrops fishery in the Clyde Sea area, Scotland. Fisheries Research 57: 169-183.

Bergmann, M., S. K. Wieczorek, P. G. Moore \& R. J. A. Atkinson, 2002b. Utilization of invertebrates discarded from the Nephrops fishery by variously selective benthic scavengers in the west of Scotland. Marine Ecology Progress Series 233: 185-198. 
Broadhurst, M. K., P. Suuronen \& A. Hulme, 2006. Estimating collateral mortality from towed fishing gear. Fish and Fisheries 7: 180-218.

Cameron, J. N., 1979. Excretion of $\mathrm{CO}_{2}$ in water-breathing animals: a short review. Marine Biology Letters 1: 3-13.

Chung, J. S. \& N. Zmora, 2008. Functional studies of crustacean hyperglycemic hormones ( $\mathrm{CHHs}$ ) of the blue crab, Callinectes sapidus - the expression and release of $\mathrm{CHH}$ in eyestalk and pericardial organ in response to environmental stress. FEBS J 275: 693-704.

Danford, A. R., L. Hagerman \& R. F. Uglow, 2002. Effects of emersion and elevated haemolymph ammonia on haemocyanin-oxygen affinity of Cancer pagurus. Marine Biology 141: 1019-1027.

deJuan, S., S. F. Thrush \& M. Demestre, 2007. Functional changes as indicators of trawling disturbance on a benthic community located in a fishing ground (NW Mediterranean Sea). Marine Ecology Progress Series 334: 117-129.

Demestre, M., P. Sánchez \& M. J. Kaiser, 2000. The behavioural response of benthic scavengers to otter-trawling disturbance in the Mediterranean. In Kaiser, M. J. \& S. J. de Groot (eds), Effects of Fishing on Non-Target Species and Habitats. Blackwell Science, Oxford: 121-129.

Dulvy, N. K. \& J. D. Reynolds, 2002. Predicting Extinction vulnerability in skates. Conservation Biology 16: 440450.

Durand, F., F. Chausson \& M. Regnault, 1999. Increases in tissue free amino acid levels in response to prolonged emersion in marine crabs: an ammonia-detoxifying process efficient in the intertidal Carcinus maenas but not in the subtidal Necora puber. Journal of Experimental Biology 202: 2191-2202.

Durand, F., N. Devillers, F. H. Lallier \& M. Regnault, 2000. Nitrogen excretion and changes in blood components during emersion of the subtidal spider crab Maja squinado (L.). Comparative Biochemistry and Physiology 127A: 259-271.

Giomi, F., S. Raicevich, A. Ferrarese, F. Pranovi, P. Di Muro \& M. Beltramini, 2007. Structural and functional heterogeneity of hemocyanin: intra- and inter-specific comparison on four species of portunid crabs (Crustacea: Portunidae). Marine Biology 151: 1237-1247.

Giomi, F., S. Raicevich, O. Giovanardi, F. Pranovi, P. Di Muro \& M. Beltramini, 2008. Catch me in winter! Seasonal variation in air temperature severely enhances physiological stress and mortality of species subjected to sorting operations and discarded during annual fishing activities. Hydrobiologia 606: 195-202.

Hagerman, L., T. Søndergaard, K. Weile, D. Hosie \& R. F. Uglow, 1990. Aspects of blood physiology and ammonia excretion in Nephrops norvegicus under hypoxia. Comparative Biochemistry and Physiology 97: 51-55.

Hall, S. J., D. Raffaelli, M. R. Robertson \& D. J. Basford, 1990. The role of the predatory crab Liocarcinus depurator in a food web. Journal of Animal Ecology 59: 421-438.

Harris, R. R. \& M. B. Andrews, 2005a. Physiological changes in the Norway lobster Nephrops norvegicus (L.) escaping and discarded from commercial trawls on the West Coast of Scotland 1 Body fluid volumes and haemolymph composition after capture and during recovery. Journal of Experimental Marine Biology and Ecology 320: 179-193.

Harris, R. R. \& M. B. Andrews, 2005b. Physiological changes in the Norway lobster Nephrops norvegicus (L.) escaping and discarded from commercial trawls on the West Coast of Scotland II Disturbances in haemolymph respiratory gases, tissue metabolites and swimming performance after capture and during recovery. Journal of Experimental Marine Biology and Ecology 320: 195-210.

Harris, R. R. \& M. Ulmestrand, 2004. Discarding Norway lobster (Nephrops norvegicus L.) through low salinity layers - mortality and damage seen in simulation experiments. ICES Journal of Marine Science 67: 127-139.

Haupt, P., S. L. Brouwer, G. M. Banch \& G. Gäde, 2006. Effects of exposure to air on the escape behaviour and haemolymph chemistry of the South African Cape Lobster Jasus lalandii. Fisheries Research 81: 210-218.

Henry, R. P. \& M. G. Wheatly, 1992. Interaction of respiration, ion regulation, and acid-base balance in everyday life of aquatic crustaceans. American Zoologist 32: 407-416.

Kelleher, K., 2005. Discards in the world's marine Fisheries: an update. FAO Fisheries Technical Paper No 470. Rome.

Lund, H. S., T. Wang, T. Chang, L. F. Pedersen, E. W. Taylor, P. B. Pedersen \& D. J. McKenzie, 2009. Recovery by the Norway lobster Nephrops norvegicus (L.) from physiological stresses of trawling: influence of season and live storage position. Journal of Experimental Marine Biology and Ecology 373: 124-132.

MacDonald, D., M. Little, N. C. Eno \& K. Hiscock, 1996. Disturbance of benthic species by fishing activities: sensitivity index. Aquatic Conservation: Marine and Freshwater Ecosystems 6: 257-268.

Mangum, C. P., 1985. Molting in the blue crab Callinectes sapidus: a collaborative study of intermediary metabolism, respiration and cardiovascular function, and ion transport. Preface. Journal of Crustacean Biology 5: 185187.

McMahon, B. R. \& J. L. Wilkens, 1983. Ventilation, perfusion and oxygen uptake. In Bliss, D. E. (ed.), The Biology of Crustacea. Vol 5: Internal Anatomy and Physiological Regulation. Academic Press, New York: 290-372.

McMahon, B. R., 2001. Respiratory and circulatory compensation to hypoxia in crustaceans. Respiration Physiology 128: 349-364.

Pranovi, F., S. Raicevich, G. Franceschini, P. Torricelli \& O. Giovanardi, 2001. Discard composition and damage to non-target species in the "rapido" trawl fishery. Marine Biology 139: 863-875.

Ramsay, K., M. J. Kaiser, A. D. Rijndorp, J. A. Craeymeersch \& J. Ellis, 2000. Impact of trawling on population of the invertebrate scavenger Asteria rubens. In Kaiser, M. J. \& S. J. de Groot (eds), Effects of Fishing on Non-Target Species and Habitats. Blackwell Science, Oxford: 151162.

Ridgway, I. D., A. C. Taylor, R. J. A. Atkinson, G. D. Stentinford, E. S. Chang, S. A. Chang \& D. M. Neil, 2006. Morbidity and mortality in Norway lobsters, Nephrops norvegicus: physiological, immunological and pathological effects of aerial exposure. Journal of Experimental Marine Biology and Ecology 328: 251-264. 
Rufino, M. M., P. Abelló, A. B. Yule \& P. Torres, 2005. Geographic. Bathymetric and inter-annual variability in the distribution of Liocarcinus depurator (Brachyura: Portunidae) along the Mediterranena coast line of the Iberian Peninsula. Scientia Marina 69: 503-518.

Santos, E. A. \& R. Keller, 1993. Effect of exposure to atmospheric air on blood glucose and lactate concentration in two crustacean species: a role of the crustacean hyperglycaemic hormone $(\mathrm{CHH})$. Comparative Biochemistry and Physiology 106A: 343-347.
Šimunović, A., 1997. Quantitative and qualitative investigations of benthic communities in the areas of mobile bottoms of the Adriatic Sea. Acta Adriatica 38(1): 77-194.

Tukey, V.W., 1953. The Problem of Multiple Comparisons. Mimeographed monograph, Princeton University.

Webster, S. G., 1996. Measurement of crustacean hyperglycaemic hormone levels in the edible crab Cancer pagurus during emersion stress. Journal of Experimental Biology 199: 1579-1585. 